\title{
EL DERECHO DENTRO DE LAS CIENCIAS FORMALES
}

\author{
THE RIGHT WITHIN FORMAL SCIENCES
}

\section{Antonio Augusto Bonatto Barcellós ${ }^{1}$ Maria Laura Moreno Fernandez ${ }^{2}$}

\section{RESUMEN}

Al derecho no se lo puede definir a través de su mismo objeto, sino desde la psico-antropología, dado que allí, es donde encontramos sus primeras manifestaciones en estado primario. Este trabajo introduce a la ciencia del derecho dentro de las ciencias formales, donde delimitaremos el objeto de estudio y estableceremos, seleccionaremos y desarrollaremos los métodos que permitan estudiar su objeto. Entendemos que el objeto y su método son condiciones necesarias para que el derecho sea una ciencia y que por sus características se encuadre dentro de las ciencias formales. El derecho a su vez debe tener una teoría jurídica que garantice la igualdad, como principio estructurador social y como base de aplicación del elemento objetivo expresado en la ley generalizable pero dentro del orden formal, impidiendo así contaminar al derecho con elementos de las ciencias causales como la conducta humana, las ideologías o los valores.

Palabras clave: Ciencias formales, objeto de estudio y método del derecho.

\begin{abstract}
Right cannot be defined through its own object, but from psycho-anthropology, since here is where we find its first manifestations in a primary state. This work introduces the science of right within the formal sciences, where we will delimit the object of study and establish, select and develop the methods that allow studying its object. We understand that the object and its method are necessary conditions for law to be a science and that due to its characteristics it falls within the formal sciences.
\end{abstract}

Keywords: Formal sciences, object of study and method of Right.

\section{INTRODUCCIÓN}

La fuerza de la naturaleza ${ }^{3}$ es la única fuerza que ha estructurado la psiquis humana, desde nuestro instinto de auto conservación hasta nuestra conciencia. La estructura psíquica está equipada para responder a sus amenazas (Freud, 2015). Desde luego estas fuerzas naturales nunca fueron

\footnotetext{
1 Phd antropologia juridica, derecho laboral. Afiliação: Universidad de Salamanca, Espanha. ORCID:https://orcid.org/0000-0002-7155-222X E-mail:antonio.barcellos@usal.es

${ }^{2}$ Estudiante de doctorado en Ciencias Sociales, especializacion Antropologia Juridica. Afiliação: Universidad de Salamanca, Espanha. ORCID:https://orcid.org/0000-0002-8830-5524 E-mail: idu019081@ usal.es

${ }^{3} \mathrm{La}$ fuerza de la naturaleza son todos los eventos que ocurren y generan daños en una población, como ejemplo los terremotos, Inundaciones, erupciones, etc.
} 
dominadas por el ser humano y esto lo hace fuente de sufrimiento para él. Esta incapacidad de dominio con fines de protección, o por demandas del instinto de auto conservación, ha impulsado al ser humano a crear elementos ideales-formales para superar algunos obstáculos de esta fuerza indómita (Freud, 2018). Es así que por necesidades primarias, el ser humano crea un mundo ideal, si bien en términos primarios estos elementos ideales tienen origen en pensamientos mágicos producto del animismo ${ }^{4}$, ese elemento imaginario permitió desarrollar las capacidades intelectuales del hombre. El plano ideal-formal permitió superar aquella situación de inferioridad con la fuerza de la naturaleza, pudiendo crear herramientas en ese plano ideal para utilizarlas en el plano natural ${ }^{5}$, posibilitando igualarse a ella y en cierta forma dominarla (Freud, 2016). El pensamiento idealformal ha logrado en algunos campos de conocimiento igualarse a la naturaleza, siendo el conocimiento ideal-formal un elemento básico para seguir construyendo el bienestar humano. En este orden ideal-formal nos encontramos por ejemplo con las ciencias formales como las matemáticas, las objetividades matemáticas y por extensión, todas las significaciones que tienen la naturaleza de ideales. Estas objetividades también tienen una relación íntima con el mundo real porque resuelven necesidades físicas que siempre se encuentran unidas a las variables posibles psíquicas humanas, en su búsqueda de igualarse y dominar a la naturaleza con fines libidinales, de protección o seguridad (Piaget, García y otros, 1989).

El derecho como objeto y como ciencia se encuentra dentro de esa entidad ideal-formal humana, el derecho está conectado con la realidad natural, aunque sea una entidad ideal-formal (Hursserl, 1967). Al derecho esta realidad lo construye en su idealidad desde el inicio hasta el punto de llegada de su aplicación, bajo la premisa de imputación del deber ser (Kelsen, 2009). Esto sucede porque el derecho es referencial de la realidad natural, pero se mantiene siempre en su órbita formal, no pudiendo salirse de ella, ni tampoco puede introducir elementos de esta realidad natural al mundo ideal-formal, sin realizar un proceso de formalización de ese objeto natural (Rizo-Patrón, 2012).

En este trabajo entendemos que al igual que ocurre con las matemáticas, el derecho tiene un carácter eidético, ${ }^{6}$ cuyo conocimiento requiere un tipo de comprensión intelectual, donde la estructura de la conciencia legitima las afirmaciones racionales (Lévi-Strauss, 2017). Husserl (2009) expresa una distinción entre "elemento lógico" como concepto objetivo y "elemento psicológico", donde entiende que el elemento lógico no es real, en cambio el psicológico sí. En este sentido, lo psíquico, influenciado por grandes cargas libidinales, estructura las relaciones lógicas como significantes, donde el desarrollo intelectual de una persona en un contexto social

${ }^{4}$ Freud, definió al animismo como: "la imposición al mundo real de las leyes de la vida anímica” (Freud, 2018, p. 110).

${ }^{5}$ En este trabajo se utilizarán tres sinónimos de natural como el término real, material o causal.

${ }^{6}$ Eidético: este término dentro de la filosofía y según Husserl entiende que el conocimiento del objeto depende del desarrollo intelectual del observador y su concepción sobre el objeto de estudio. 
determinado, puede integrar o desintegrar las relaciones como significantes dentro de su estructura psíquica y proyectar la misma operación con las personas jurídicas como lo es el Estado o la Sociedad (Piaget, 1979). Lo psíquico como elemento material o causal, crea los elementos más abstractos bajo una lógica que cohesiona los hechos y les da coherencia bajo un vínculo relacional afectivo y las interioriza a la estructura psíquica del "yo" consciente, esta es una característica propia del mecanismo psíquico y esto evidencia la profundidad del instinto de auto-conservación (Freud, 2016).

Según Husserl la cuestión ontológica, modo de ser del dominio formal y sus leyes analíticas, es un proceso donde cae o se vacía de contenido material los conceptos, produciendo algo indeterminado, general y vacío. Esta definición es completamente validada al derecho, aunque creemos que el derecho como ciencia formal es un proceso que no tiene desde su inicio contenido conceptual material, siendo el derecho algo indeterminado en el sentido de Rousseau "Si es preciso obedecer por la fuerza, no se necesita obedecer por deber, y si no está forzado a obedecer, no se está obligado. Esta palabra derecho, no añade nada a la fuerza; no significa nada absolutamente" (Rousseau, 2011, p. 39), apuntando que, en este trabajo se traduce el "deber y derecho" en significación social como generalidad formalizante. En este mundo ideal-formal del derecho, nunca hay conceptos con contenidos materiales que pertenecen a las ciencias causales, como por ejemplo "La conducta humana". En el mundo ideal formal hay relaciones y significaciones de ánimus $^{7}$ o deseos humanos que trabajan en ese mundo ideal y que pertenecen a la estructura psíquica del "yo". Aunque una parte de esta idealidad busca ser materializada a través de la libido objetal del "yo", y lo hace a través de la conducta humana en su complitud, este elemento no puede ser formalizado dentro del derecho (Laplanche, 2000).

Para trabajar dentro del derecho primero necesitamos identificar los elementos ideales formales, como por ejemplo el acto humano con significación social coherente, este elemento le pertenece al "yo", y es el elemento por el cual éste busca RELACIONARSE con el otro ideal. Dentro del derecho y con los elementos ideales-formales, como el acto humano ya vacío de contenido objetal-material que se ligaba a través de la conducta humana (Isaacs, 1930). Ahora se puede operar dentro de las ciencias formales. Aportando la siguiente idea: "para trabajar dentro del derecho todos los elementos que se introduzcan en él, que provengan de las leyes o del orden jurídico y de la conducta humana, deben ser depurados y formalizados para realizar las operaciones ideales-formales correspondientes". El derecho es una ciencia formal porque estudia las formas de relacionarse entre sujetos exitosamente socializados, esta forma de relacionarse es creada por el conjunto de la sociedad a través de principios y valores que en este trabajo se definen como

\footnotetext{
${ }^{7}$ Interprétese como sustantivo de animismo, definido en la nota al pie 2.
} 
"significantes" y que se integran en la estructura psíquica del "yo", y consisten en representaciones de intereses producto de las proyecciones afectivas en un entorno social. El objeto de estudio del derecho lo identificamos como el elemento objetivo relacional de la norma ideal, positiva y animista.

\section{HIPÓTESIS}

En este trabajo partimos desde la hipótesis general como supuesto de que las fuerzas de la naturaleza han forzado al ser humano a construir un orden ideal para poder igualar sus fuerzas ante esta naturaleza y crear un entorno seguro y propicio para desarrollar y estabilizar su elemento anímico, logrando un cierto dominio en el mundo natural. Se busca demostrar que el animismo es de origen afectivo/anímico y este animismo ha creado al idealismo con la finalidad de expresarse en el mundo ideal formal para integrar y adaptarse dentro de esa idealidad a la realidad. La naturaleza de ese ánimus, que es parte de la estructura psíquica del "yo", de origen narcisista e ideal, prevalece sobre el sentido de la realidad y es una herramienta de adaptación compleja que lo lleva a operar en planos ideales y abstractos, para ello se desarrollará un apartado de psicología de Freud (2012), de introducción al narcisismo (Wundt, 1929).

La segunda hipótesis que presentamos se basa en el supuesto de que el derecho es ideal y referencial de la realidad natural, es un proceso necesario por el cual se busca integrar la realidad del exterior hacia la realidad psíquica del ser humano y lo hace para cumplir con la finalidad de crear un entorno seguro, donde lo ideal pueda analizar lo natural o real, e interpretar que tan amenazante es el objeto o su situación y evitar el peligro contra la estabilidad psíquica o física.

La tercera hipótesis radica en que el derecho está dominado por principios estructuradores sociales como son el principio de seguridad y el principio de igualdad, pero dentro de la sociedad, el derecho como regulador de las relaciones sociales, debe tratar a los sujetos bajo un manto de igualdad formal y esto solo se puede realizar a través de una teoría jurídica, dado que las teorías tienen la finalidad de garantizar la igualdad, pues brindan las bases de aplicación de la ley generalizable a todos los casos que caen dentro del campo de la norma" (Bacigalupo, 1999). Nosotros proponemos utilizar la teoría pura del derecho de Kelsen, como un instrumento idóneo que funciona como un transcriptor de la ley al derecho a través de la expresión del elemento objetivo en la norma, y que bajo el principio de igualdad y con nuevos elementos conceptuales que se utilizarán dentro de la teoría pura del derecho, como el acto humano con significación social coherente, nos permitirán la transcripción conceptual de la ley, en el elemento objetivo imputado a un acto humano con significación social coherente (Moreno Fernandez, 2019). 
La cuarta hipótesis sobre la que se basa el presente trabajo, es que el derecho como elemento ideal-formal permite realizar la integración del mundo real desde afuera hacia adentro y lo integra en la estructura psíquica del "yo", y para integrarlo, debe transcribirlo de forma ideal con esa lógica jurídica que está relacionada con los principios estructuradores sociales como el principio de seguridad y el principio de igualdad, y por ello es fundamental mantener ese idealismo del derecho bajo cánones de seguridad específicas, como por ejemplo contenido en una teoría pura del derecho que estructure los elementos conceptuales y aplique el derecho bajo un sistema formal puro (Bacigalupo, 1999).

Este trabajo mantiene una línea ideal-lógica-formal del derecho extraída de la escuela del positivismo jurídico de Kelsen, en la cual vamos a identificar la naturaleza del derecho con el mundo ideal formal, su objeto de estudio y desarrollo de sus elementos conceptuales se harán a través de las obras de Kelsen, en su teoría pura, para demostrar que Kelsen también consideraba al derecho como una ciencia ideal-lógica-formal, y perteneciendo a este mundo, debe trabajar con elementos del mundo ideal formal, o realizar la formalización de cada elemento ajeno a este orden. Este proceso de formalización se exige no solo porque el objeto de estudio del derecho sea un elemento ideal formal, sino porque toda la lógica del derecho y del animismo normativo tienen una composición puramente formal. Para ello vamos a describir cada elemento ideal formal que Kelsen nombra en su teoría pura y utilizaremos los métodos deductivos típicos de esta ciencia formal.

El resto del presente trabajo se organiza de la siguiente manera. En el apartado tercero se desarrollará la hipótesis primera donde se darán las bases de las ciencias formales, se explicará el origen de estas ciencias y se la comparará conceptualmente con el derecho. En el apartado cuarto se desarrollará la hipótesis tres, en la cual se explica que los principios estructuradores sociales, como el principio de seguridad y el principio de igualdad también estructuran al derecho y lo condicionan en su práctica obligándole a ser aplicado bajo una teoría, es decir, en su método y aplicación. En el apartado quinto se desarrollará la hipótesis segunda donde se dan las razones para determinar al objeto de estudio del derecho dentro de las ciencias formales. En los apartados sexto y séptimo se desarrollará la hipótesis cuarta donde se establece el concepto del derecho, el deber ser, como categoría lógica y el método para aplicarse. En el apartado ocho se desarrollará la hipótesis tercera y cuarta donde se explica la transcripción de la ley al derecho a través de la teoría pura del derecho de Kelsen (2009) y a través de la regla del derecho. En el apartado noveno se darán finalmente las conclusiones de este trabajo. 


\section{LAS CIENCIAS FORMALES Y EL DERECHO}

Entendemos a las ciencias formales como las ciencias de sistemas formales. Estos sistemas están compuestos por tres elementos: 1. Conjunto de símbolos primitivos; 2. Reglas de formación o combinación de estos símbolos primitivos; y 3. Mecanismo deductivo que permita transformar unas combinaciones de signos en otras diferentes de un modo preciso (Haack, 1991). El conjunto de símbolos y las reglas de formación conforman el lenguaje formal. El sistema es la suma del lenguaje formal; un mecanismo deductivo de este lenguaje formal y los mecanismos deductivos no pueden operarse en abstracto, sino que es preciso escoger un lenguaje formal concreto y un mecanismo deductivo especifico como por ejemplo el que usa la lógica proposicional (Grassmann y Tremblay, 1997). La tarea que aquí se impone, es tratar de demarcar cual es el tipo de conocimiento que podríamos denominar formal. Caracterizamos a una ciencia por sus dos elementos: 1. La delimitación de su objeto de estudio; y 2. El establecimiento, selección y desarrollo de métodos que permitan estudiar a su objeto. Siendo estos dos, el objeto y su método condiciones necesarias de las ciencias, si alguno de estos faltare no puede haber ciencia. La lógica y la matemática son ciencias puras abstractas y formales porque no tienen contenido específico o especial, son ciencias de la forma y la forma sería el objeto de estudio de estas ciencias (Franklin, 1994).

El derecho es formal porque estudia las formas de relacionarse entre sujetos exitosamente socializados tramitadas a través de un objeto y expresadas en un significante social representado en el Estado Moral, y ese es el campo de acción del derecho. La forma de relacionarse tiene un significante social cuando se integran en dos elementos conceptuales del derecho, primero el objeto de estudio del derecho como el elemento objetivo relacional de la norma ideal, positiva y animista y segundo el acto humano con significación social coherente. Para aplicar el derecho a un caso concreto primero se deben formalizar todos aquellos elementos que no están formalizados, en este sentido, por ejemplo, de la conducta humana extraemos el acto humano y de la norma animista extraemos el elemento objetivo relacional, una vez formalizados los elementos producto del proceso transcriptivo del elemento objetivo de la ley al derecho, podrá realizarse la imputación a través del deber ser que dentro del derecho ya no es Moral, sino que es Formal. Formalizados todos los elementos, realizamos la imputación a través del método deductivo, en este sentido seria: El elemento objetivo relacional de la norma debe ser imputado al acto humano con significación social coherente y esta significación, debe ser coherente con los principios estructuradores sociales que son definidos en este trabajo como significantes propios de un Estado Moral (Rousseau, 2011). 
Dentro de las ciencias formales encontramos otra característica que se comparte con el derecho y ayuda a afirmar la hipótesis de que el derecho es una ciencia formal, su objeto de estudio esta indeterminado como bien señalo Rousseau: "Si es preciso obedecer por la fuerza, no se necesita obedecer por deber, y si no está forzado a obedecer, no se está obligado. Esta palabra derecho, no añade nada a la fuerza; no significa nada absolutamente" (Rousseau, 2011, p. 39), apuntando que, en este trabajo, se traduce el "deber y derecho" en significación social como generalidad formalizante, producto de una ley de la cual emana la moral del Estado.

Observamos que el derecho como las ciencias formales tiene su objeto de estudio indeterminado, no porque no tenga a priori, acto humano o sujeto imputable, sino porque el objeto se centra en la significación social coherente de un acto relacional contenido en el elemento objetivo de la norma, esa significación solo puede crearse en el momento en que un sujeto de derecho busca relacionarse con otro sujeto y actúa, y en esa relación de origen afectiva, se encuentra la significación de ese acto y que es la que debe ser coherente con los actos nombrados que se describen en la ley positiva producto de un Estado Moral. Por otro lado, observamos que la indeterminación del deber o del derecho a priori no es caprichosa, tiene su fundamento en permitir integrar la realidad que le impone la fuerza de la naturaleza a través de la idealidad, creada por la sociedad e impuesta al individuo en continuo desarrollo. El proceso de integración en la estructura psíquica del "yo" del individuo es continua y va integrándose en esas dos fases la natural o real y la psíquica o ideal. Esta indeterminación del deber o del derecho a priori es una característica de la plasticidad con la que se trabaja en el plano ideal y permite al individuo adaptarse en el mundo natural a través del mundo ideal (Wundt, 1929).

4. EL PRINCIPIO DE IGUALDAD ESTRUCTURAL SOCIAL Y DEL DERECHO

"El pacto social establece entre los ciudadanos una igualdad tal, que se comprometen todos bajo las mismas condiciones y, por tanto, que deben gozar todos los mismos derechos" (Rousseau, 2011, p. 62). "En lugar de destruir la igualdad natural, el pacto fundamental sustituye, por el contrario, con igualdad moral y legitima lo que la Naturaleza había podido poner en desigualdad física entre los hombres y que, pudiendo ser desiguales en fuerza o en talento, advienen todos iguales por convención o derecho" (Rousseau, 2011, p. 53). En estas dos citas a Rousseau de su obra "El Contrato Social" observamos dos expresiones del principio de igualdad con destinos diferentes, la primera, es observar que a través del mundo ideal y lógico se busca superar las incapacidades naturales que posee el ser humano y la segunda, una vez superada de forma ideal la superioridad de la naturaleza, el pacto viene a crear una igualdad social, es decir, entre todos los 
integrantes de un grupo social determinado serán relacionados de forma igual a la aplicación del derecho como expresión de la ley o el pacto social (Lévi-Strauss, 2006).

Es observable que las incapacidades del hombre contra la fuerza de la naturaleza habían dejado una vivencia traumática, la cual daría lugar a la creación del mundo ideal, en el mundo mágico animista, los dioses obedecían a sus leyes anímicas y esto se veía expresado en su cultura. Además de ello, el hombre debió resolver otras dificultades que se encontraban en su mismo nivel humano, otros humanos quizás más desarrollados en inteligencia y fuerza, lo que ha llevado a preguntarse ¿porque estos humanos más fuertes y más inteligentes cederían a sus privilegios y aceptarían igualarse con otros más débiles?, como bien identificó Wundt (1906) y luego Freud (2018) la renuncia era afectiva y animista, esa renuncia no se daba en la etapa adulta del hombre, sino que se fijaba en su más tierna infancia (Osterrieth, 1993). Para organizar un grupo social, hacerlo estable y seguro era necesario ordenar primero las relaciones afectivas recurriendo otra vez al mundo ideal para crear en él aquella coherencia ideal con las fuerzas y que en la realidad no existían (Freud, 2018). Es evidente que estamos frente a un trasfondo afectivo del ser humano que luego será estructurado a todo el grupo con la forma de "MORAL". La igualdad como principio estructural es una herramienta ideal, creada por los impulsos afectivos del ser humano en relación con otro sujeto y esta igualdad solo es posible trabajarla en un plano ideal y dentro de una ciencia formal. No solo para superar esa realidad limitante, sino para mantener al grupo seguro, confiando en que sus lazos parentales y afectivos son estables y se refuercen a través de una igualdad afectiva o MORAL. También esta igualdad esta indeterminada cuando aparece en la ley, opera en un plano puramente abstracto y su componente básico es el significante social, el derecho a través del principio de igualdad tiene sentido porque están los otros sujetos en relación social y este sentido se tramita a través de objetos, los cuales todos responden a un Estado Moral (Lévi-Strauss, 2017).

Dentro del derecho la igualdad como principio formal también es exigida, y para poder trabajar en su aplicación dentro del derecho es necesaria como bien identifico Bacigalupo (1999, p. 39) "una teoría jurídica, dado que estas tienen la finalidad de garantizar la igualdad, pues brindan una base de aplicación de la ley generalizable a todos los casos que caen dentro del campo de la norma". En este sentido creemos que una teoría jurídica es necesaria, para aplicar en la práctica el derecho como único elemento de garantía del tratamiento igualitario en las relaciones, y es aquí donde aportamos la idea de que para trabajar con este principio dentro de una teoría jurídica formal, es necesario comprender su naturaleza, es decir, la igualdad formalizada o como un elemento puramente abstracto e ideal, la cual solo puede ser trabajada dentro de las ciencias formales y la teoría del derecho es la herramienta que garantiza la aplicación de esa igualdad en las relaciones ante el ESTADO MORAL y su LEYES (Bacigalupo, 1999). 


\section{LA DETERMINACIÓN DEL OBJETO DE ESTUDIO DEL DERECHO EN} EL ORDEN FORMAL

Para comenzar a desarrollar este apartado vemos fundamental separar primero el orden jurídico y sus leyes de la ciencia del derecho para poder analizar al derecho de forma aislada, entendemos al ordenamiento jurídico y sus leyes como elementos que pertenecen a las ciencias causales, al contener en las mismas varios elementos causales como la conducta humana, ideologías y valores, en cambio entendemos que el derecho pertenece a las ciencias formales porque su objeto es ideal y abstracto, es además un elemento indeterminado y solo es operable a través de las formas contempladas dentro de una teoría del derecho para determinar al objeto del derecho bajo el principio de igualdad, y en este sentido utilizaremos la teoría pura del derecho de Kelsen (Haack, 1991). Observamos en las leyes y su orden jurídico, un elemento animista al creer de forma fideísta ${ }^{8}$ que "El contenido de una ley, producto de la razón humana, es suficiente para dominar la conducta humana, aplicándole elementos valorativos morales e ideológicos" (Popper, 1994).

Si comenzamos a estructurar el razonamiento con respecto al Estado como persona pública moral, concepto extraído de la teoría social de Rousseau (2011), observamos varios elementos fundamentales que construyen el objeto de estudio del derecho y coinciden con los elementos estructurales que Wundt (1929) y luego Freud (2018) describieron en sus obras sobre los estudios Tótem y Tabú y sobre el incesto. En la obra del Pacto Social de Rousseau (2011) se describe en el contrato social que el acuerdo que se propugna entre los individuos les permite superar las diferencias físicas y convertirlas en igualdad moral y esta es la fuerza soberana del Estado moral (Rousseau, 2011). Evidenciando en la moral las transferencias afectivas creadas producto de las relaciones parentales, las cuáles sirvieron como superadoras de los límites impuestos por lo natural o físico y pasaron a proyectarse en el plano animista, ideal y abstracto, siendo este un plano idóneo para la estructura psíquica (Freud, 2016). Esto permite inducir la idea de que, en principio, lo que fuera un pensamiento mágico y animista producto de la dureza impuesta por la naturaleza, ayudó a estimular un pensamiento ideal y abstracto más lógico con la realidad, pero sin capacidad de poder anular esa transferencia afectiva que se ancla en la estructura psíquica del ser humano y que es proyectada a los elementos ideales o abstractos como lo es el PACTO SOCIAL (Freud, 2018). A partir de esta observación reflejamos un proceso psíquico, por el que creemos se genera un elemento primordial de la estructura social, funcional a la MORAL, ese elemento es el principio de igualdad, los elementos afectivos que crearon la moral y pudieron crear una igualdad ideal de origen afectivo,

${ }^{8}$ Fideísta: definición de Karl Popper, quien afirmaba que la razón es buena y su racionalismo crítico se apoyaba en último término en una "fe" en la razón (Popper. K, 1994). 
que no existe en el orden material o físico, y que hoy vemos reflejado en las leyes y en el derecho se exigen, es también el mismo elemento que se transfirió de la moral al Estado; del Estado a las leyes y de las leyes al derecho (Lévi-Strauss, 2017).

Este acuerdo de voluntades para superar en lo ideal-social los límites y dificultades naturales humanas a través de elementos ideales como las leyes, no son derechos sino elementos ideales indeterminados que aún deben determinarse en derechos/deberes y que siempre tienen un objeto por el cual la conciencia proyecta y tramita esas cargas afectivas transformadas en ideales (Freud, 2012). Este dato de las cargas afectivas no es menor dentro del mundo del derecho, debido a que son los elementos que formarán la significación social de un acto humano y por tanto es un elemento precursor al derecho. En este sentido basta observar las descripciones de las obras de Lévi-Strauss, en "las estructuras elementales del parentesco" (2017), donde se describe a través de los estudios del incesto, como las relaciones primarias entre las familias a través del sistema de reciprocidad, tenían una base afectiva generadora de seguridad y potenciadora de la integración social, por la cual fueron entretejiendo pequeños "acuerdos" de intercambios parentales manteniendo esos profundos lazos afectivos como garantía de protección, a través de ritos con los significantes morales como los que hoy se observan en los actos simbólicos nacionales, que se protegen en las Constituciones modernas y que dieron lugar al actual Estado de derecho (Boas, 1901). En este sentido la reciprocidad tradicional entre grupos estaba primero dominada por estas relaciones afectivas, las cuales a día de hoy se conservan e interactúan en la vida en sociedad y la estructuran en un esquema social mayor proyectada como MORAL, también se puede observar cómo se transfiere y transforma esta MORAL en autoridad, en este sentido observamos que la moral y la autoridad son dos caras de una misma moneda, donde las cargas y lazos afectivos, se representan sobre una persona ideal, moral, superior como lo es el Estado, el cual es competente por su carga afectiva traducida en autoridad MORAL para implementar derechos y deberes, manteniendo los preceptos morales protegidos y estables (Boas, 1901). Hasta ahora hemos descripto como los elementos afectivos se transformaron en elementos morales y como se proyecta esta moral en una persona ideal a la cual esa misma idealidad moral el da autoridad, de momento estamos describiendo las bases elementales que llevarán a crear luego al derecho (Freud, 2018).

En este sentido el derecho existe no porque aparezca escrito en una ley actual, esto solo hace que la ley sea positiva y el derecho no aparece aquí solo por ser positivo sino además, por ser objetivo y formal o indeterminado, lo que le permite entrar dentro de un proceso formal por el cual se determina en la significación de un acto humano y a través de la imputación del deber ser, cómo una categoría lógica formal. En este proceso el derecho que es formal y ya está determinado o completo porque ya se imputo a su significación social. Concluido este proceso formal, el resultado de estas operaciones formales, serán utilizadas para aplicarlas dentro del orden jurídico o legal, que 
pertenece al mundo causal por tener elementos como los valores o ideales propios del orden psíquico y en este punto se termina de proceder si ese resultado formalizado pertenece al Estado Moral y valorativo o no y por tanto, desarrollar las consecuencias de este proceso. En este punto del proceso fuera del orden formal se trabaja con elementos psíquicos puros relacionales afectivos el cual busca concretarse a través de un acto humano con una significación social. Este proceso es producto de una relación entre sujetos socializados tramitada mediante un objeto, sujetos socializados a quienes por ese vínculo relacional y afectivo integran o desintegran diversas significaciones sobre esa relación entre sujeto y objeto. Este tipo de significaciones producto de las relaciones humanas tramitadas a través del derecho es el elemento más abstracto creado por la estructura psíquica humana en un entorno social y es en este sentido que el derecho como ciencia formal asimila a esa significación, producto de la relación entre sujetos a través de objetos y es donde esa significación se integra, posibilitando determinar el derecho concreto de esa relación y proceder a la imputación de la significación social a un acto humano. Esta significación junto al acto humano deben ser coherentes con la finalidad de la construcción ideal del Estado como persona moral (Rousseau, 2011). Este es un ejemplo de la manifestación de una ciencia formal en un plano puramente abstracto, cuyos resultados serán aplicados en el orden jurídico, estas relaciones vinculantes tienen un componente afectivo y son las que crean diversos significantes y deben ser acordes con el Estado como persona moral fijado en el pacto social. Por ello deducimos que las significaciones creadas por componentes puramente afectivos fueron las precursoras de la moral en el ámbito social y luego se plasmaron en el derecho a través las leyes (Freud, 2018).

El sujeto se relaciona de forma afectiva, la afectividad es el nutriente ideal de la estructura psíquica del yo y del orden ideal, dado que este fue enteramente narcisista en su etapa fetal y luego del nacimiento, ese narcisismo no desaparece sino que se transforma, crea el mundo ideal y se va proyectando en ideales, al principio mágicos, es un yo ideal consagrado al amor ególatra de la niñez, el "yo" ideal, adornado con todas sus perfecciones, en la etapa adulta intenta repetir lo que en la niñez, incapaz de renunciar a la perfección, perfecciona sus ideales (Freud, 2012, p.33). Las relaciones afectivas con otro sujeto se tramitan a través de objetos, y observamos que esa afectividad nunca puede materializarse, pero si puede expresarse y representarse en un plano ideal. Este plano ideal es el único posible y viable para expresar los estadios afectivos y equilibrar los conflictos de la vida anímica a través de los actos que contienen los significantes. En el derecho estudiamos el elemento objetivo de la relación, que se expresa en la ley y se convierte finalmente en una significación social determinada, y ya en este punto podemos definir el objeto de estudio del derecho como el elemento objetivo relacional de la norma positiva, ideal y animista (Moreno Fernandez, 2019), en este sentido vemos que la norma contiene al derecho con elementos valorativos y fenómenos psíquicos, en este punto, cuando se busca aplicar el derecho, se utiliza la teoría pura del 
derecho para extraer ese elemento objetivo identificado como parte del derecho, y se realiza el proceso de imputación a través de las premisas lógicas para trabajar con el principio de igualdad formal. Con esta operación dejamos atrás a la norma positiva ideal y animista que solo transporta el elemento objetivo del derecho, y por medio de este proceso de transcripción contenido en la teoría pura del derecho, se realizan las operaciones de imputación con la cual se termina de formar, completar o determinar el derecho. Esto sucede cuando una institución o juez realiza las operaciones imputativas dentro de la teoría pura del derecho y resuelve en sentencia firme ese elemento objetivo, identificado como significante imputable a un objeto por el cual se tramita una relación social. Es en este sentido que el derecho es un elemento objetivo estructurador, en el caben todas las relaciones declaradas en las leyes o pacto social, porque estas relaciones tienen una finalidad social que es la expresión máxima del ethos de una sociedad (Lévi-Strauss, 2017). El derecho es formal porque su objeto es abstracto e indeterminado y está condicionado por el principio de igualdad, es en el campo formal donde se termina de formar la estructura del elemento significante, que en la ley era indeterminado y que es producto de la relación entre sujetos socializados a través de un objeto, y luego con la teoría pura de Kelsen y su instrumento de imputación de la regla del derecho adaptada, se realiza la imputación del deber ser (Kelsen, 2009).

\section{EL DEBER SER COMO CATEGORÍA DE LA LÓGICA}

Comenzamos citando partes de la Teoría Pura del Derecho de Kelsen (2009), para exponer que dicho autor concibió al derecho como un elemento perteneciente a las ciencias formales: "La teoría pura del derecho se esfuerza por eliminar este elemento ideológico moral al brindar una definición de la norma jurídica totalmente independiente de la noción de norma moral y al afirmar la autonomía del derecho respecto de la moral” (Kelsen, 2009, p. 55) "La regla del derecho establece una relación entre una condición y una consecuencia, afirmando que si la condición se realiza la consecuencia debe ser. Esta expresión deber ser está desprovista de todo sentido moral" (Kelsen, 2009). En este sentido, no creemos que Kelsen ignore la moralidad de la norma jurídica o sus leyes dado que estas están llenas de estos elementos morales, lo que entendemos es que Kelsen buscaba a través de su teoría transformar la igualdad moral en igualdad formal, para realizar las operaciones de imputación del derecho bajo cánones de seguridad, reforzando así el principio de seguridad de una sociedad. Observamos que la igualdad dentro del mundo del derecho debe tratar a los significantes de actos humanos como relaciones no solo con otros sujetos, sino también con el Estado Moral.

"El deber ser tiene un sentido puramente lógico, como elemento de imputación es una relación funcional específica establecida entre los elementos de un sistema dado, el derecho" 
(Kelsen, 2009). En este sentido entendemos que la teoría de Kelsen fue creada no solo para garantizar el principio de igualdad dentro de la aplicación del derecho, sino que observamos en la formalidad que Kelsen le otorga para determinar al derecho o concretizarlo. En esta regla del deber ser, se observa que Kelsen comprendía al derecho como un elemento de las ciencias formales, al afirmar que el deber ser es una categoría lógica, es decir las reglas formales como parte de un sistema de funciones, el derecho también lo era. Entendemos que en este punto Kelsen buscaba que el derecho sea operable bajo el principio de igualdad formal y para ello era necesario crear una teoría con todos sus elementos pertenecientes y operables dentro de las ciencias formales, como único método para expulsar del derecho elementos ideológicos o valorativos que pertenecen a las ciencias causales y que permiten aplicar el principio de igualdad. Para ello es necesario separar la norma o ley del derecho, entendemos que la ley expresa los elementos objetivos del derecho permitiendo así operar enteramente bajo una ciencia formal como lo sería por ejemplo: la lógica matemática la cual es también una ciencia formal. Si observamos la teoría de Kelsen vemos que entiende a la norma dentro de un sistema, este sistema tiene reglas y estas reglas tienen a su vez una relación funcional, en este sentido creemos que Kelsen entiende al derecho y su teoría como elementos todos pertenecientes a las ciencias formales por medio de las cuales, el derecho y su proceso decantan en la formación final de una sentencia la que contiene el derecho aplicado. En otras palabras, observamos que Kelsen entendió al derecho como funcional, esta función del derecho es integrar las derivaciones lógicas de las relaciones al sistema definido como Estado Moral (Bacigalupo, 1999).

\section{ESTABLECIMIENTO, SELECCIÓN Y DESARROLLO DEL MÉTODO PARA APLICAR EL DERECHO DENTRO DE UN SISTEMA FORMAL}

Para Kelsen en su teoría pura, "el derecho es un sistema de normas a los cuales los hombres prestan o no conformidad" (2009, p.36). En este sentido observamos cómo se mezcla al derecho con las normas o las leyes y su ordenamiento jurídico.

Nuestra aportación y aclaración es justamente decir que el derecho no es la norma sino que es un elemento objetivo indeterminado que es expresada por la norma en su proceso de transcripción. En este sentido la ley o norma es una estructura valorativa de ideas animistas, porque se cree de forma fideísta que las normas valorativas son las que ordenan o guían las conductas de los hombres en uno u otro sentido y esto es incorrecto. Lo que observamos aquí es una expresión animista de la ley que no tiene entidad para obligar a los hombres a comportarse de una manera determinada, y esto fue observado por Rousseau en la frase que ya se mencionó en el apartado de introducción, "Si es preciso obedecer por la fuerza, no se necesita obedecer por deber, y si no está 
forzado a obedecer, no se está obligado. Esta palabra derecho, no añade nada a la fuerza; no significa nada absolutamente" (Rousseau, 2011, p. 39). Por ello volvemos a mencionar la idea la cual es un método de trabajo, de separar la norma o leyes del derecho porque son objetos diferentes que pertenecen a ciencias diferentes, que están relacionadas por la estructura social, pero de una forma mucho más compleja. La norma o ley solo es transcriptora de los elementos objetivos del derecho, pero la norma no está dentro del sistema del derecho. En este sentido las leyes o normas pertenecen a las ciencias normativas que están en el orden de la psico-antropología, dado que son estructuras simbólicas cargadas de valores e ideologías, en definitiva, es animista porque por medio de ella se intenta imponer las leyes de la vida anímica al mundo real. En cambio, el derecho pertenece a las ciencias formales porque dentro de su sistema extrae el elemento objetivo de la norma y su función es integrar el elemento objetivo a las significaciones producto de las relaciones humanas, realiza la formalización de todos los elementos transcriptos a través del principio de igualdad formal, luego de realizar la formalización y sus derivaciones lógicas, se integra en la estructura social.

Separado el mundo de las leyes y su ordenamiento jurídico del derecho, ahora podemos pasar a desarrollar el método para estudiar el derecho de forma aislada de cualquier elemento ajeno al orden formal. Si observamos el derecho, éste se forma de significantes producto de un gran grupo heterogéneo de relaciones con trasfondo afectivo entre individuos. Estas relaciones entre sujetos, crean significantes sociales que deben ser coherentes con la Moralidad del Estado (Rousseau, 2011, p. 59). Estas relaciones que crean significantes se tramitan a través de objetos, estos pueden ser ideales o materiales, por ello se define a la conciencia como objetal, porque la conciencia siempre va dirigida a objetos (Berguer y Luckmann, 2008); la razón, como producto de la estructura psíquica y la conciencia del "yo", integra los hechos, conductas o actos, los cohesiona y busca hacerlos coherentes con su estructura biográfica, no busca hacerlos real, esta cohesión y coherencia es una necesidad psico-fisiológica del ser humano, esos objetos por los cuales los seres humanos se relacionan son usados junto con la relaciones ideales con la finalidad de integrarse a la sociedad y sentirse seguro, y por ello identificamos al derecho o deber con la relación que se crea y actúan como significantes sociales (Isaacs, 1930).

Entendemos al derecho como un objeto de estudio dentro de las ciencias formales porque es un elemento abstracto, ideal e indeterminado que debe ser determinado dentro del campo del derecho a través de su teoría del derecho, en este sentido la teoría no solo es transcriptiva sino que también es garante de la aplicación del principio de igualdad formalizada. El derecho está contenido por la norma, pero necesita de una teoría que lo pueda transcribir, es decir, aislar el elemento objetivo y expresar su significación social a través del uso del sistema formal. Como ya se mencionó al inicio de este apartado, Kelsen decía que "el derecho es un sistema de normas a los cuales los 
hombres prestan o no conformidad" (2009, p.36), y nosotros proponemos que el derecho es un sistema de elementos objetivos ideales los cuales están destinados a cumplir con una función social a través de su significante, la función del derecho es tramitar las relaciones entre sujetos y la finalidad del derecho es que esta tramitación sea segura o mantenga estable el principio de seguridad dentro del sistema aplicando el principio de igualdad, como principios estructuradores sociales (Lévi-Strauss, 2017).

Como se mencionó en el apartado tres de este trabajo, la ciencia formal es una ciencia de sistemas formales compuesta por tres elementos, 1-Conjunto de símbolos, 2- Reglas de formación o combinación de símbolos y 3- Mecanismos deductivos transformando las combinaciones de signos en otros diferentes de modo preciso. El estudio del lenguaje formal y los mecanismos deductivos no pueden hacerse en abstracto, sino que es preciso escoger un lenguaje formal concreto y un mecanismo deductivo específico a través de la lógica proposicional. En derecho resulta interesante identificar qué área del significante se puede imputar a una significación emitida por un acto humano bajo la igualad del Estado moral y sus leyes.

Todos los significantes son producidos por relaciones sociales y todas las relaciones sociales tienen una finalidad social que es igual al ESTADO MORAL y este Estado moral mantiene y refuerza el principio de seguridad. La ciencia formal es indeterminada hasta que se completa o determina a través de la forma, y se hace con exclusividad. El lenguaje del derecho se extrae de todos los elementos objetivos que expresa la norma a través del proceso de transcripción, estos elementos objetivos son los símbolos y a ellos los ordenamos según la regla del derecho en su imputación del deber ser y reglas de formación que son los principios como el principio de igualdad.

Las reglas de formación del derecho se ordenan a través de dos principios estructurales de la sociedad y del derecho, ellos son: a)- El principio de seguridad-Afectivo Moral, es el que está en la cúspide del sistema y si este es afectado crea una desestabilización social; y b)- El principio de igualdad, es la regla para producir todas las relaciones sociales y se aplica dentro del derecho.

Bajo estos principios estructuradores debemos ahora integrar los demás símbolos o elementos objetivos teniendo en cuenta que sin igualdad no puede haber seguridad jurídica ni social. El principio de seguridad es afectivo y moral y en este nivel no debe ser formalizado ningún elemento porque solo funciona como elemento aglutinador y estable, está ya formado y es referencial. No sucede igual con el principio de igualdad, en este principio es necesario que todos los elementos sean formalizados porque aquí reside la idealidad y que fuera de la igualdad, era moral y valorativo. Dentro del derecho, la igualdad formal no permite trabajar con elementos valorativos, sino que exige la igualdad formal, es decir elementos objetivos junto con sus reglas definidas, por ello se debe formalizar todos los elementos que entran a determinar el derecho y para ello es necesario trabajar con este principio formalizador ideal, creando símbolos y reglas. El 
derecho aún no está determinado, sino que se determinará cada vez que se aplica la regla del derecho bajo este principio de igualdad. Esto se expresa así: solo hay seguridad moral si se realiza un tratamiento general bajo el principio de igualdad formal. Para que exista la igualdad es necesario que se opere el derecho dentro de una teoría jurídica construida dentro las ciencias formales, evitando de esta forma introducir cualquier elemento que no corresponda al derecho (Bacigalupo, 1999).

Símbolos del derecho: 1 . EOE= Elementos objetivos expresados en la norma; 2 . $\mathrm{R}=$ Relaciones; 3. Ss= Significación social; 4. $K^{9}=$ Deber ser formula de imputación; 5 . AH= Acto humano con significación social coherente.

Reglas de formación para combinar los símbolos del derecho bajo el principio de igualdad formal:

1. $\mathrm{EOE}=$ Es una fórmula básica de formación que se expresa en la norma.

2. $\mathrm{R}=$ Es una fórmula básica de formación.

3. Ss= Fórmula compuesta por un símbolo EOE, seguida del símbolo Ss y seguida de un símbolo R. Es una fórmula básica del lenguaje.

4. $\mathrm{K}=$ Cualquier fórmula compuesta por un símbolo $\mathrm{R}$ seguida del símbolo Ss y seguido de cualquier tipo EOE, es una formula básica del lenguaje.

5. $\mathrm{AH}=$ Cualquier fórmula construida según las reglas 1 (EOE), $2(\mathrm{R}), 3(\mathrm{Ss})$ y $4(\mathrm{~K})$, seguida del símbolo $5(\mathrm{AH})$

6. Solamente las expresiones formadas según las reglas de formación entre 1 al 5 son formulas básicas de formación del lenguaje del derecho y ninguna otra lo es.

En este sentido podemos decir que se utiliza un elemento objetivo expresado en la norma (EOE) y que a través de una relación $(\mathrm{R})$ entre sujetos socializados se producen significaciones sociales (Ss) que deben ser imputadas según el deber ser (K) a cualquier acto humano con significación social coherente $(\mathrm{AH})$.

El derecho es un sistema de elementos objetivos expresados en la norma o ley por la teoría pura del derecho, la cual permite la transcripción de esos elementos objetivos dentro del sistema del derecho, el cual tiene la función de integrar las relaciones a la estructura social a través de derivaciones lógicas.

\footnotetext{
${ }^{9}$ Se utiliza la $\mathrm{K}=$ para recordar la regla de imputación de Kelsen, K de Kelsen.
} 


\section{LA TRANSCRIPCIÓN DE LA LEY AL DERECHO A TRAVÉS DE LA REGLA DE LA TEORÍA PURA DEL DERECHO}

En este trabajo se aporta la idea de que la teoría pura del derecho, es un elemento de transcripción de la ley, del ordenamiento jurídico y del sentir étnico. Siendo la transcripción un proceso de expresión de la ley, donde el derecho escoge, analiza y aplica los elementos objetivos ya desprovistos de todo elemento valorativo e ideológico y los imputa a una significación social de un acto a través del deber ser como categoría lógica, conteniendo el principio de igualdad y resguardando el principio de seguridad (Bacigalupo, 1999).

El orden jurídico como orden subordinado pierde la funcionalidad valorativa, moral e ideológica cuando de sus normas se procede a la transcripción de la ley por el derecho, extrayendo de ella elementos objetivos. Cuando se da esta transcripción excluyente se encuentra dentro de la ciencia del derecho y por tanto se transcribe el derecho al caso concreto (Jiménez Cano, 2013). Pudiendo así distinguir y separar al orden jurídico, que contiene al pacto social y sus leyes, de la ciencia del derecho positivo puro y excluyente que crea la teoría pura del derecho para responder al principio de igualdad, manteniendo estable al principio de seguridad. Esta hipótesis desarrolla la idea de que la teoría pura del derecho es un elemento de transcripción de la ley, del ordenamiento jurídico y del sentir étnico. Siendo la transcripción un proceso de expresión de la ley al derecho de forma excluyente, donde el derecho sólo escoge, analiza y aplica los elementos objetivos ya desprovistos de todo elemento valorativo, moral o ideológico al caso concreto. La importancia de realizar operaciones lógicas formales radica en su capacidad de operar bajo el principio de igualdad, lo que refuerza las estructuras psico-antropológicas aumentando la percepción de seguridad (LéviStrauss, 2017). También entendemos en esta hipótesis que las necesidades psico-fisiológicas de seguridad y reciprocidad se exigen y llegan a su máximo desarrollo ideal, lógico-formal desde que termina la formación psíquica del "yo". Estos órdenes superiores, psico-antropológicos, son los que hacen todos los juicios valorativos morales e ideológicos, dejando al derecho libre de valores y con la capacidad de operar a nivel ideal-objetivo, lógico-formal (Wundt, 1906). En este sentido vemos que el derecho es una técnica social que tiene la finalidad de crear un orden seguro y tiene la función de ordenar e integrar las relaciones humanas en función de los principios proclamados en el pacto fundamental descrito por el principio de seguridad (Isaacs, 1933).

La transcripción de la ley al derecho a través de la regla del deber ser, indica el sentido de relación establecido por todo elemento objetivo entre una condición y su consecuencia, esta relación tiene el carácter de imputación y puramente lógico desprovisto de toda significación moral o 
jurídica, ya que la imputación es una categoría lógica y no una noción moral o jurídica (Kelsen, 2009).

\section{CONCLUSIONES}

Entendemos que la creación de los Estados de Derechos modernos, fundamentados en la Teoría social de Rousseau "Pacto Social" lleva consigo no solo los elementos estructurales como los principios fundamentales de la organización social, sino también traen aparejados la necesidad de crear elementos ideales abstractos para ordenar las relaciones humanas dentro de una sociedad. En este sentido creemos que la realidad natural o la fuerza de la naturaleza empujó al hombre a crear y proyectarse en un mundo ideal y abstracto, aunque también entendemos que esto es posible porque la naturaleza de la estructura psíquica tiene esta entidad ideal y abstracta. Esta línea de investigación en la idealidad como creación psíquica es la que hace posible comprender el orden humano a través del derecho, nos permite entender cómo se estructura lo ideal en lo natural y a partir de allí se desarrolla de forma muy compleja porque se trabaja con muchas variables algunas pertenecen al mundo natural causal y otras al mundo ideal formal.

Observamos también que, dentro del mundo ideal formal, el derecho tiene la función de integrar las relaciones sociales a una estructura más grande y compleja como es la sociedad actual y que exigido por esa igualdad ideal, debe hacerlo a través de derivaciones lógicas para completar el derecho en una relación entre sujetos tramitada a través de objetos. Para hacer esta integración a través de una derivación es necesario utilizar la metodología de las ciencias formales y operar todos los objetos una vez se le haya aplicado el proceso formalizante. Por otro lado también concluimos que esta formalización del derecho es necesaria para poder garantizar y reforzar el principio de seguridad no solo jurídica sino también social estructural.

Finalmente concluimos que el derecho no solo pertenece a las ciencias formales por su objeto de estudio y su método, sino por la función que tiene dentro de la sociedad que como sistema debe integrar las relaciones a una estructura social a través de las derivaciones lógicas con el fin de reforzar y generar seguridad.

\section{REFERENCIAS BIBLIOGRÁFICAS}

Artigas M. Lógica y Ética en Karl Popper, Eunsa, Navarra, 2001.

Bacigalupo, E., "Empirismo y Teorías Jurídicas (La Utilización de las Teorías Jurídicas en la Práctica Judicial), Ed. Universidad Autónoma de Madrid, 19989, Revista Jurídica 1 (1999): pp. 37 $-46$. 
Calisto Badesa, Ignasi Jané y Ramon Jansana, 2007, Elementos de la lógica formal, $2^{\text {a }}$ edición, Octubre de 2007, Ed. Ariel, Barcelona.

Franklin, James (1994). The formal sciences discover the philosophers' stone. Studies in History and Philosophy of Science Part A 25 (4):513-533

Franz Boas, The Eskimo of Baffin"s Land and Hudson Bay, Ed. Kissinger Publising, 1lc, 2010.

Haack, Susan (1991) Filosofía de las lógicas, (Amador Antón trad.) Madrid: Cátedra.

Husserl, E. 2009, Lógica formal y trascendental, Ensayo de una crítica de la razón lógica, Traducción de Luis Villoro y Antonio Zirión, México D.F: UNAM.

Husserl, E., 1967, Investigaciones Lógicas, Tomo I, traducción Morente y Gaos. Madrid: Revista de Occidente, pp. 394-395.

Isaacs, Susan. 1930, Intellectual Growth in Young Children. Londres.

Lévi-Strauss, C. (2006): Tristes Trópicos, Publicado en francés por Librairie Plon, París: traducido por Noelia Bastard, 1955, Edición en Castellano por Editorial planeta.

Lévi-Strauss, 2017, Las Estructuras Elementales del Parentesco, Ed. Espasa libros, Barcelona.

Freud, S. (2016): Esquema del Psicoanálisis, Madrid: Alianza.

Freud, S. (2015): El Malestar en la Cultura, Madrid: Alianza.

Freud, S. (2018): Tótem y Tabú, Madrid: Akal.

Freud, S. (2012): Introducción al narcisismo y otros ensayos, Madrid: Alianza.

Freud, S. (2016): El caso Dora, fragmentos de análisis de un caso de histeria, Buenos Aires, Amorrortu.

Sussan Sussan Isaacs, (1933): Develoment in Young children, London: George Routledge \& Sons.

Jiménez Cano, Roberto. M, 2013, <<Una Defensa del Positivismo Jurídico Excluyente〉>, Isonomía, (39) 83 - 126.

Kelsen, Hans, 2009, Teoría Pura del Derecho, Ed. Eudeba, $8^{\circ}$ reimpresión, Buenos Aires.

Laplanche. Jean, 2000, "Pulsion et Instinct”, publicado en Adolescence, 18(2), 649-668.

Osterrieth, Paul. 1993, Psicología Infantil, versión española de Gonzalo Gonzalvo Mainar, Ediciones Morata, Madrid.

Piaget, García y otros, 1989, Hacia una lógica de las significaciones, Barcelona, Gedisa.

Piaget, J.1979, Adaptación vital y psicología de la inteligencia, México, Siglo XXI.

Popper, K.1994, La sociedad abierta y sus enemigos, Paidós, Barcelona.

Rizo-Patrón, Rosemary, 2012, Objetividades matemáticas, ¿reales o ideales?, Reflexiones desde el pensamiento de Edmund Husserl, Areté, Revista de filosofía, Vol. XXIV, Nº1, PP. 181-201. 
Rousseau, Jean-Jaques, 2011, El contrato social, Traducido por Fernando de los Ríos, Espasa Libros, Madrid.

Vilajosana, Josep María, 2006: "El positivismo jurídico convencionalista”, en Ramos Pascua, José Antonio y Rodilla, Miguel Ángel (Eds.), El positivismo jurídico a examen. Estudios en homenaje a José Delgado Pinto. Salamanca, Universidad de Salamanca, pp. 521-536.

Winfried Karl Grassmann y Jean - Paul Tremblay 1997, Matemática discreta y lógica, una perspectiva desde la ciencia de la computación”, Traducido por PRENTICE HALL, INC, Ultima impresión 2010, Ed. PEARSON EDUCACION S.A. Madrid.

Wundt, W. (1929): La Evolución de las Filosofías, Traducido del Alemán por Emilio R. Sadia, Madrid.

Wundt, W. (1920): Vörkerpsychologe, (10 vols.). Leipzig: Engelmann, 1900 - 1920.

Trabalho recebido em 23 de setembro de 2021

Aceito em 01 de outubro de 2021 